\title{
The asymmetric responses of stock prices in US market
}

\author{
Woan Lin $\mathrm{Beh}^{1 *}$ and Wen Khang Yew ${ }^{1}$ \\ ${ }^{1}$ Faculty of Science, Universiti Tunku Abdul Rahman, 31900 Kampar, Perak, Malaysia
}

\begin{abstract}
Machine learning and data analytics are so popular in making trading much more efficient by helping the investors to identify opportunities and reduce trading costs. Before applying suitable predictive modelling algorithms, it is crucial for investors or policymaker to understand the nature of the stock data properly. This paper investigates the dependency of macroeconomic factors against the stock markets in the United States using the nonlinear Autoregressive Distributed Lag (NARDL) approach. The analysis considered the Dow Jones Industrial Average Index, NASDAQ Composite Index, and S\&P 500 Index. Macroeconomic factors in this country such as consumer price index, export, interest rates, money supply, real effective exchange rates, total reserves, and gold price are considered in this study. In the findings, the NARDL approach shows that the Dow Jones Industrial Average Index and S\&P500 Index are having bi-directional positive asymmetric effects to each other in the short run. In short-run, increasing the consumer price index is found to have a negative effect on Dow Jones Industrial Average Index but with a positive effect on S\&P500 Index. In conclusion, this study aids investors and other market participants in making a more efficient investment decision.
\end{abstract}

\section{Introduction}

The stock market plays an important role in the financial sector by providing a platform for investors to buy and sell the shares of the listed companies. In the past, investors made decisions based on information on market trends and risks. Recently, machine learning and data analytics are making trading much more efficient by helping investors with the ability to identify opportunities and reduce trading costs. Big data which combined with machine learning making a decision based on logic than estimates. However, stock market data often acquire singular features such as a high degree of persistence on shocks, trend, high volatility over time, and cointegrate with other macroeconomic factors [1]. As an investor, it is important to understand the characteristics of the stock data properly before making any decision. Studies have shown that the volatility in macroeconomic factors is likely to affect stock price either in a positive or negative direction [2-3].

\footnotetext{
* Corresponding author: behwl@utar.edu.my
} 
Over the past few years, researchers have employed cointegration analysis and causality analysis in studying the relationship between stock markets and macroeconomic factors. Ordinary least square (OLS) and vector autoregressive (VAR) models are the two most common models used in investigating time series data in the earlier stage. However, these models may cause spurious regression problem due to non-stationary [1]. A cointegration test is then introduced to study the relationship between non-stationary time series data [46]. Autoregressive Distributed Lag (ARDL) cointegration technique [7-8] is introduced and become one of the famous approaches to studying the cointegration of the series. It then extended to non-linear Autoregressive Distributed Lag (NARDL) which assumes asymmetric adjustment between variables of interest [9]. Problems may arise if the nonlinearity is not considered when modeling the relationship between macroeconomic effects and stock returns $[3,10]$. The majority of economic and financial variables exhibit a non-linear and asymmetric interaction over time [11]. Factors such as economic crises, wars, policy-making, political, and rapid changes in the business cycle may cause unforeseen changes in the functioning of time series, which particularly draw structural breaks, asymmetric effects, and leverage effects [11]. Then the stock indices are likely to behave non-linearly under these conditions.

Several articles have addressed the relationship between stock markets and macroeconomic factors. A study conducted by [12] examined the symmetric as well as the asymmetric effect of macroeconomic factors against stock prices of Karachi Stock Exchange 100 index and vice versa. The results suggested that macroeconomic factors and stock prices are asymmetric in the short term whereas the relationship becomes symmetric in the long term. NARDL is applied in studying the impacts of the exchange rate, inflation, money supply, and the interest rate on Vietnam's major stock index (VNIndex) [13]. Results have shown that money supply has a positive impact on VNIndex with the magnitude of the negative component higher than the positive component. NARDL is applied to study the effects of the nominal exchange rate, industrial production index, and the interest rate on stock prices in Turkish [14]. They found that both the industrial production index and exchange rate affect asymmetrically stock prices.

This study attempts to analyse the cointegration and asymmetric effect between the stock indices in the United States (U.S.) and its macroeconomic factors. Our study expands the work of [15] by constructing the NARDL approach to determine the long term and short term effects, including the asymmetric relationship in the estimation model. The study conducted in [15] assumes symmetric effects between the underlying variables. The relationship between the macroeconomic factors and the stock price is identified by using the linear model (ARDL approach). However, economic variables are usually incorporate asymmetric properties over the business cycles $[16,17]$. Hence, the study conducted in this paper will discover the hidden asymmetric effect between the chosen variables. According to [15], the U.S. money supply, export value, real effective exchange rate, and the gold price are the determinant factors to the U.S. stock markets in a symmetric direction. This study chooses the monthly data from three stock markets: Dow Jones Industrial Average (DJI) Index, NASDAQ Composite (NDQ) Index, and S\&P500 (SP) Index as the dependent variables while consumer price index, export, interest rate, money supply, real effective exchange rate, total reserves excluding gold, and gold price as the independent variables. Three models are constructed based on the suggested independent variables. Our empirical results show that increase in the consumer price index is found to have a negative effect on Dow Jones Industrial Average Index but with a positive effect on S\&P500 Index in the short-run. NARDL approach shows that the Dow Jones Industrial Average Index and S\&P500 Index are having bi-directional positive asymmetric effect on each other in the short run.

The remainder of this paper is organized as follows. The data and models will be discussed in Section 2. Section 3 discusses the empirical findings. Concluding remarks are given in Section 4. 


\section{Methodology}

\subsection{Data}

This study employs monthly data with 10 variables from Jan 2002 to June 2019. Dow Jones Industrial Average Index (dji), NASDAQ Composite Index $(n d q)$, and S\&P500 Index $(s p)$ have been chosen to represent the U.S. stock market. Consumer Price Index in the U.S. (uscpi) is chosen as when unanticipated inflation occurs, stock prices will decrease at the time of the announcement causing corporate income to reduce due to rapid increase in costs and the slow adjustment in output prices [18]. Besides, this study employed export value in the U.S (usex) as [19] found that the response of stock index has a positive dynamic impact on export by using Vector Auto-Regressive (VAR) model. Furthermore, this study includes the interest rate in the U.S. (usint) as the independent variables [20-22]. Likewise, numerous studies proved that the monetary policy has a close relationship with the stock markets. Hence, this study includes the money supply in the U.S. (usms) in the form of M2. Consequently, real effective exchange rate in the U.S. (usreer) are chosen as [23] stated that exchange rate related highly on both output and input price in which directly affecting the value and international competitiveness of firms. Furthermore, this study employed gold price (gold) [24-26]. Finally, the total reserves excluding gold in the U.S. (usrs) [27-28] are been included in the analysis. The data is collected from the Organization for Economic Cooperation and Development database, International Monetary Fund database, Board of Governors of the Federal Reserve System (U.S.) database, Bank for International Settlements database, International Monetary Fund database, Yahoo Finance, macrotrends.net, and Investing.com.

\subsection{Models}

This study aims to determine the asymmetric effect of macroeconomic factors in the U.S. (uscpi, usex, usint, usms, usreer, usrs, and gold) on the stock markets in the U.S. (dji, ndq and $s p)$. All the variables are transformed into natural logarithm form to remove the heteroscedasticity problem. Thus, three models are constructed as follows:

Model 1: $\ln \_d j i=\mathrm{F}\left(\ln \_n d q, \ln \_s p, \ln \_u s c p i, \ln \_u s e x, \ln \_u s i n t\right.$, ln_usms, ln_usreer, ln_usrs, ln_gold)

Model 2: ln_ndq $=\mathrm{F}\left(\ln \_s p, \ln \_d j i, \ln \_u s c p i\right.$, ln_usex, ln_usint, ln_usms, ln_usreer, ln_usrs, ln_gold)

Model 3: $\ln \_s p=\mathrm{F}\left(\ln \_d j i, \ln \_n d q, \ln \_u s c p i\right.$, ln_usex, ln_usint, ln_usms, ln_usreer, ln_usrs, In_gold)

This study used the NARDL approach proposed by [9] to conduct the cointegration analysis. Our model regresses the dependent and independent variables with distributed lags by investigating their relationship in short- and long-run dynamics. [8, 29-30] proved that if the regression model is obtained by using OLS with non-linear ARDL lags, the estimator can be explained in Normal distribution even though the sample size is small. This model can identify both the linear and non-linear long-run relationships between model variables [8, 29 -30]. This approach can distinct short-run and long-run effects of estimation variables and measuring them without any duplication of model parameters when compare with other vector error correction models [8, 29-30]. Another advantage of using this model is that its cointegration rank does not need to be similar and this assists the freedom in using the different variables in the model which can't be applied to other vector error correction models [8, 29-30]. Unit root tests can be used to confirm the order of integration. Moreover, the case of nonlinear cointegration is applied when the variables with their positive and negative components are verified to have cointegration [31]. The possible reasons for having nonlinearity are caused by noise, extreme volatility, or asymmetric adjustment process. 
The NARDL modelling allows us to detect the asymmetric effects both in the short- and long-run using positive and negative partial sum decompositions. It can be used to analyse non-stationarity and nonlinearity in the form of an unrestricted error correction model. A general NARDL model can be written as follow:

$$
y_{t}=\delta^{+} x_{t}^{+}+\delta^{-} x_{t}^{-}+\mu_{t}
$$

where $y$ is the dependent variable, $\delta^{+}$and $\delta^{-}$are the coefficients of the regressors $x_{t}$, decomposed as:

$$
x_{t}=x_{0}+x_{t}^{+}+x_{t}^{-}
$$

where $x_{t}^{+}$and $x_{t}^{-}$are the partial sums of positive and negative change in $x^{t}$ as follows:

$$
\begin{aligned}
& x_{t}^{+}=\sum_{j=1}^{t} \Delta x_{j}^{+}=\sum_{j=1}^{t} \max \left(\Delta x_{j}, 0\right) \\
& x_{t}^{-}=\sum_{j=1}^{t} \Delta x_{j}^{-}=\sum_{j=1}^{t} \min \left(\Delta x_{j}, 0\right)
\end{aligned}
$$

Equation (2) can be written as the $\operatorname{NARDL}(\mathrm{p}, \mathrm{q})$ form, which is the asymmetric error correction model (AECM):

$\Delta y_{t}=\rho y_{t-1}+\theta^{+} x_{t-1}^{+}+\theta^{-} x_{t-1}^{-}+\sum_{j=1}^{p-1} \varphi_{j} \Delta y_{t-1}+\sum_{j=0}^{q}\left(\pi_{j}^{+} \Delta x_{t-j}^{+}+\pi_{j}^{-} \Delta x_{j-t}^{-}\right)+\varepsilon_{t}$

where $\theta^{+}=-\rho \delta^{+}$and $\theta^{-}=-\rho \delta^{-}$.

We estimate the optimal NARDL model by dropping insignificant variables and lags from general to a specific procedure. For NARDL, Equation (5) is estimated using the OLS method. Then, the presence of nonlinear cointegration is tested by using the bound testing approach proposed by [8]. Finally, the short-run and long-run asymmetries between variables are estimated. Wald test is used to examine the short-run $\left(\pi^{+}=\pi^{-}\right)$and long-run $\left(\theta^{+}=\theta^{-}\right)$ asymmetries. The asymmetric cumulative dynamic multiplier effect is derived as follows:

$$
m_{k}^{+}=\sum_{j=0}^{k} \frac{\partial y_{t+j}}{\partial x_{t}^{+}}, m_{k}^{-}=\sum_{j=0}^{k} \frac{\partial y_{t+j}}{\partial x_{t}^{-}}, k=0,1,2, \ldots
$$

Note that as $k \rightarrow \infty$, the $m_{k}^{+} \rightarrow \delta^{+}$and $m_{k}^{-} \rightarrow \delta^{-}$.

\section{Results and discussion}

The stationarity of the variables is examined using the Augmented Dickey-Fuller (ADF) unit root test [32]. ADF unit root test has the null hypothesis of the series is non-stationary. Based on the result, all the variables are integrated at first difference. Hence, we can proceed to estimate the NARDL framework.

For the NARDL bound test results, the F-statistics in Model 1 fall between the lower and upper bounds of critical value at a 5\% level of significance. Hence, no conclusion may be drawn for Model 1. However, there is cointegration among variables in Model 2 as the Fstatistics is higher than the upper critical bound value at a $5 \%$ level of significance. This suggests that the NASDAQ Composite Index has a long-run relationship with the U.S. macroeconomic factors. Model 3 is found to have no cointegration as the F-statistics fall below the lower critical bound at $10 \%$ level of significance.

After performing the bound test, we proceed to estimate the long-run coefficients for these models. The estimated results are summarised in Table 1. We applied the Wald test to ascertain 
the suitability of the nonlinear model as well as confirm the long-run asymmetries. The null hypothesis of the Wald test is assuming the positive and negative relationship of each variable is symmetry. In Model 1, the positive and negative changes of export are having a negative impact on Dow Jones Industrial Average Index. However, only the negative change of export has a significant impact on Dow Jones Industrial Average Index. Wald test result suggests that export has a symmetry effect to the Dow Jones Industrial Average Index. Hence, we conclude export has a symmetrical effect to the Dow Jones Industrial Average Index in the long-run. The other variables in Model 1 show only exist symmetry effects to Dow Jones Industrial Average Index.

Besides, when NASDAQ Composite Index is the dependent variable (Model 2), the positive (negative) change of the Dow Jones Industrial Average Index has a significant negative (positive) impact on the NASDAQ Composite Index. However, only the negative changes of S\&P500 Index and money supply have a significant positive impact on the NASDAQ Composite Index. The asymmetries effects among significant variables were then confirmed by using the Wald test. Furthermore, no variables is having significant asymmetries impact to S\&P500 Index (Model 3) in the long-run which ascertains the bound test result in Table 1. All the variables form in Model 3 is having a symmetry effect on the S\&P500 Index.

Table 1. Estimation result of the long run models.

\begin{tabular}{|c|c|c|c|}
\hline & Model 1 & Model 2 & Model 3 \\
\hline Variable & $\ln d j i$ & $\ln n d q$ & $\ln s p$ \\
\hline constant & - & $7.446139 * * *$ & - \\
\hline $\ln \_d j i^{+}$ & - & $0.815734^{* * *}$ & 13.85554 \\
\hline$l \ln _{-} d j i^{-}$ & - & $-0.769410 *$ & -21.04144 \\
\hline$W_{l n \_d j i}$ & - & $6.793682 * * *$ & 1.089805 \\
\hline $\ln n n d q^{+}$ & -39.24239 & - & -13.21625 \\
\hline ln_ndq- & -16.69910 & - & -1.985388 \\
\hline$W_{l n \_n d q}$ & 0.595145 & - & 0.158097 \\
\hline $\ln s s p^{+}$ & 46.46754 & 0.360795 & - \\
\hline $\ln \_s p^{-}$ & -0.673775 & $1.513724 * * *$ & - \\
\hline$W_{l n \_s p}$ & 1.779606 & $6.939146^{* * *}$ & - \\
\hline ln_uscpi $i^{+}$ & 52.54849 & - & -10.21680 \\
\hline $\ln \_u s c p i^{-}$ & 254.4978 & - & -20.17330 \\
\hline$W_{\text {ln_uscpi }}$ & 0.995993 & - & 0.005423 \\
\hline ln_usex ${ }^{+}$ & -25.77912 & - & - \\
\hline ln_usex ${ }^{-}$ & $-34.52552 *$ & - & - \\
\hline$W_{\text {ln_usex }}$ & 0.251827 & - & - \\
\hline $\operatorname{ln\_ } u \sin t^{+}$ & -3.548336 & - & 0.323082 \\
\hline ln_usint ${ }^{-}$ & 1.895487 & - & 0.733334 \\
\hline$W_{\text {ln_usint }}$ & 2.378159 & - & 0.014555 \\
\hline ln_usms ${ }^{+}$ & - & 0.187610 & - \\
\hline ln_usms ${ }^{-}$ & - & $4.916653 * *$ & - \\
\hline$W_{\text {ln_usms }}$ & - & $4.498470 * *$ & - \\
\hline ln_usreer ${ }^{+}$ & -21.95356 & - & -51.21967 \\
\hline ln_usreer ${ }^{-}$ & -34.41519 & - & -44.40134 \\
\hline$W_{\text {ln_usreer }}$ & 0.032446 & - & 0.016270 \\
\hline $\ln \_$gold $^{+}$ & - & - & -12.40412 \\
\hline $\ln \_g o l d^{-}$ & - & - & -8.876061 \\
\hline$W_{\text {ln_gold }}$ & - & - & 0.059227 \\
\hline
\end{tabular}


Table 2 shows the summary of the nonlinear short-run dynamic model for Model 1, 2, and 3. The expected negative sign of error correction term (ECT) is highly significant at a $1 \%$ level of significance in all models. The coefficient of ECT in Model 3 is -0.1675 , which implies that the deviation from the long-term growth rate in the NASDAQ Composite Index is corrected by $16.75 \%$ by the coming month. The positive sign ECT in Model 1 implies that it is not converging from a short-run into the long-run, giving further information that there is no longrun nonlinear relationship between the variables. In Model 3, the ECT term is negative and significant at a $1 \%$ level of significance, but the coefficient is relatively small (-0.0009), which implies there is no long-run nonlinear relationship between the variables.

Table 2. Estimation results of the short-run models.

\begin{tabular}{|c|c|c|c|}
\hline & Model 1 & Model 2 & Model 3 \\
\hline Variable & $\Delta l n \_d j i$ & $\Delta \ln n n d q$ & $\Delta l n \_s p$ \\
\hline$\Delta l n \_d j i_{t}^{+}$ & - & $-0.474567 * * *$ & $0.641350^{* * *}$ \\
\hline$\Delta l n \_d j i_{t}^{-}$ & - & $-0.756885^{* * *}$ & $0.742966^{* * *}$ \\
\hline$\Delta l n \_n d q_{t}^{+}$ & $-0.169002^{* * *}$ & - & $0.273695^{* * *}$ \\
\hline$\Delta l n \_n d q_{t}^{-}$ & $-0.151740^{* * *}$ & - & $0.221803 * * *$ \\
\hline$\Delta l n_{-} s p_{t}^{+}$ & $1.174639^{* * *}$ & $1.610145^{* * *}$ & - \\
\hline$\Delta l n_{-} s p_{t}^{-}$ & $1.148245^{* * *}$ & $1.857079 * * *$ & - \\
\hline$\Delta l n \_u s c p i_{t}^{+}$ & $-0.658056^{* * *}$ & - & $0.595230^{* * *}$ \\
\hline$\Delta l n \_u s i n t_{t}^{-}$ & $-0.033015^{* * *}$ & - & $0.025712^{* * *}$ \\
\hline$E C T_{t-1}$ & $0.001201^{* * *}$ & $-0.167535 * * *$ & $-0.000934 * * *$ \\
\hline
\end{tabular}

In the short-run, the increase and decrease of NASDAQ Composite Index and S\&P500 Index have a significant effect on the Dow Jones Industrial Average Index (Model 1). In contrast, the consumer price index impact significantly to the Dow Jones Industrial Average Index only during inflation. It is found that a decrease in U.S. interest has a significant effect on Dow Jones Industrial Average Index. In Model 2, the estimates show that the Dow Jones Industrial Average Index and S\&P500 Index impact significantly to NASDAQ Composite Index regardless of positive or negative changes. Furthermore, increase and decrease in the Dow Jones Industrial Average Index and NASDAQ Composite Index have a significant effect on the S\&P500 Index (Model 3) and have a nonlinear relationship in the short-run. Increase in the inflation rate and decrease in the interest rate in short-run show a positive impact on the S\&P500 Index in Model 3.

The robustness of the models is ascertained by several diagnostic tests such as the BreuschGodfrey Serial Correlation Lagrange multiplier (LM) test, Autoregressive Conditional Heteroscedasticity (ARCH) test for heteroscedasticity, CUSUM and CUSUMSQ test (5\% critical line) for stability. Table 3 summarises the results of diagnostic tests. Models 1 and 3 fulfil the NARDL assumption of no autocorrelation, homoscedasticity, and stability. However, Model 2 suffers from a heteroscedasticity problem at a 5\% level of significant and yet it is accepted as it meets other assumptions.

Table 3. Diagnostic statistics.

\begin{tabular}{|c|c|c|c|}
\hline & Model 1 & Model 2 & Model 3 \\
\hline ARCH(1) & 1.371814 & $5.766454 * *$ & 2.346104 \\
\hline LM(12) & 0.600553 & 0.548649 & 0.808456 \\
\hline CUMSUM & Stable & Stable & Stable \\
\hline CUMSUMSQ & Stable & Slightly unstable & Stable \\
\hline
\end{tabular}




\section{Conclusion}

This paper attempts to analyse the relationship between the U.S. stock market and macroeconomic factors in the U.S., using monthly data from Jan 2002 to June 2019 with three different models specifications. This study has some important findings. First, we found that there is no asymmetric cointegration between the Dow Jones Industrial Average Index and the chosen macroeconomic factors (Model 1) in the long-run (due to the ECT is positive). There is also no asymmetric cointegration between the S\&P500 Index and the macroeconomic factors (Model 3) in the long-run. However, the Dow Jones Industrial Average Index and S\&P500 Index are having bi-directional positive asymmetric effect on each other in the short run. In the short run, increasing in the consumer price index is found to have a negative effect on Dow Jones Industrial Average Index but with a positive effect on S\&P500 Index. From the prospect of stock investors, it is advisable to stay alert to the Dow Jones Industrial Average Index during inflation. As our results show that the stock index will plunge when the goods and services price increase in the short-run. Second, we found that there is long-run asymmetric cointegration between the NASDAQ Composite Index and the macroeconomic factors (Model 2). These results provide some suggestions to the monetary policymakers. They are recommended to be more alert when announcing any new policy change that might spark persistent shock to the stock market.

This research is supported in part by UTAR Research Centre, Centre of Mathematical Science from the Universiti Tunku Abdul Rahman, Malaysia.

\section{References}

1. M.B. Shrestha, G.R. Bhatta, JFDS 4, 71 - 89 (2018)

2. M. Bahmani-Oskooee, S. Saha, Glob. Finance J. 31, 57 - 72 (2016)

3. G. Lee, D. Ryu, J. Bus. Econ. and Manag. 19, 343 - 359 (2018)

4. R.F. Engle, C.W. Granger, Econometrica 55(2), 251 - 276 (1987)

5. S. Johansen, K. Juselius, Discussion paper 88-05 (1988)

6. S. Johansen, K. Juselius, Oxf. Bull. Econ. Stat. 52, 169 - 210 (1990)

7. M.H. Pesaran, Y. Shin, Econometrics and economic theory in the $20^{\text {th }}$ Century, (Cambridge University Press, 371 - 413, 1999)

8. M.H. Pesaran, R.J. Smith, Y. Shin, J. Appl. Econ. 16, 289 - 326 (2001)

9. Y. Shin, B. Yu, M. Greenwood-Nimmo, Festchrift in honor of peter schmidt, (Springer, New York, 281 - 314, 2014)

10. D. Ryu, H. Kim, H. Yang, Appl. Econ. Lett. 24, 826 - 830 (2017)

11. A. Ahmed, L. Amine, K.N. Duc, Energy Policy 65, 567 - 573 (2014)

12. B.H. Chang, S.K.O. Rajput, SAJBS (2018)

13. D.T.B. Van, H.H.G. Bao, A nonlinear autoregressive distributed lag (nardl) analysis on the determinants of Vietnam's stock market, in International Econometric Conference of Vietnam, Springer, Cham, 363 - 376 (2019)

14. H. Kaya, B. Soybilgen, 2019. EABD 19, 293 - 300 (2019)

15. W.L. Beh, W.K. Yew, JCR. 7, $68-74$ (2020)

16. S. N. Neftci, JPE. 92(2), $307-328$ (1984).

17. B. Falk, JPE. 94(5), 1096 - 1109 (1986)

18. R.H. DeFina, Bus. Rev. 3, 3 - 12 (1991) 
19. M. Hasanujzaman, MPRA Paper (2016)

20. N.F. Chen, R. Roll, S.A. Ross, J. Bus. 59(3), 383 - 403 (1986)

21. W.K. Wong, H. Khan, J. Du, The Singap. Econ. Rev. 51, 31 - 51 (2006)

22. A. Humpe, P. Macmillan, Appl. Fin. Econ. 19, 111 - 119 (2009)

23. N.L. Joseph, Trad. \& Reg. 7, 306306 (2002)

24. J. Beckmann, R. Czudaj, The North Am. J. Econ. and Finance 24, 208 - 222 (2013)

25. K. Kanjilal, and S. Ghosh, Resour. Policy 41, 135 - 142 (2014)

26. M. Shahbaz, M.I. Tahir, I. Ali, I.U. Rehman, The North Am. J. Econ. and Finance 28, 190 - 205 (2014)

27. S. Ray, RHSS 2, $46-60$ (2012)

28. O.O. Akinlo, O. Awolowo, Int. J. Bus. Fin. Res. 9, 69 - 76 (2015)

29. S. Ghatak, J.U. Siddiki, J. Appl. Stat. 28, 573 - 583 (2001)

30. P.K. Narayan, S. Narayan, Energy policy 35, 6549 - 6553 (2007)

31. C.W.J. Granger, G. Yoon, Hidden cointegration, in Royal Economic Society Annual Conference 2002, Royal Economic Society 92 (2002)

32. D.A. Dickey, W.A. Fuller, J. Am. Stat. Assoc. 74, 427 - 431 (1979) 